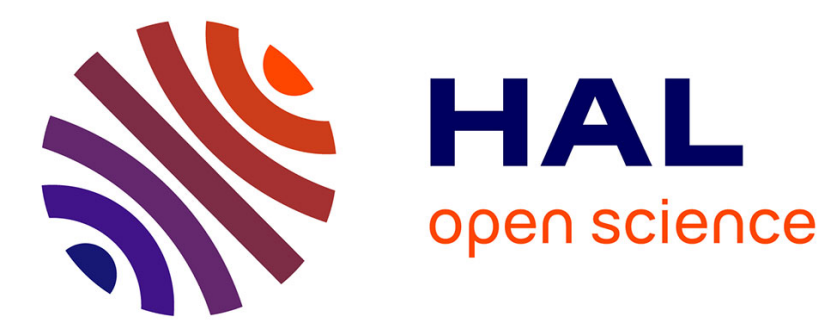

\title{
Performance of hybrid turbo codes
}

\author{
Patrick Adde, Ramesh Pyndiah, Claude Berrou
}

\section{To cite this version:}

Patrick Adde, Ramesh Pyndiah, Claude Berrou. Performance of hybrid turbo codes. Electronics Letters, 1996, 32 (24), pp.2209 - 2210. hal-02489028

\section{HAL Id: hal-02489028 \\ https://hal.science/hal-02489028}

Submitted on 24 Feb 2020

HAL is a multi-disciplinary open access archive for the deposit and dissemination of scientific research documents, whether they are published or not. The documents may come from teaching and research institutions in France or abroad, or from public or private research centers.
L'archive ouverte pluridisciplinaire HAL, est destinée au dépôt et à la diffusion de documents scientifiques de niveau recherche, publiés ou non, émanant des établissements d'enseignement et de recherche français ou étrangers, des laboratoires publics ou privés. 
encoding by an extended $\mathrm{BCH}$ code. This new matrix $\left(N_{c}\right.$ columns of $N$ symbols) is used as an interleaver. Every row is encoded by the RSC code, with code memory $v$, as illustrated in Fig. 1. The redundancy $Y$ of this code can be punctured: it is organised as $N_{y}$ columns of $N$ symbols. The code rate $R$ of the hybrid turbo code is

$$
R=\frac{K N_{c}}{N\left(N_{c}+N_{y}\right)}
$$

where $K / N=R_{B C H}$ is the $\mathrm{BCH}$ code rate and $N_{c} /\left[N_{c}+N_{y}\right]=R_{R S C}$ is the RSC code rate.

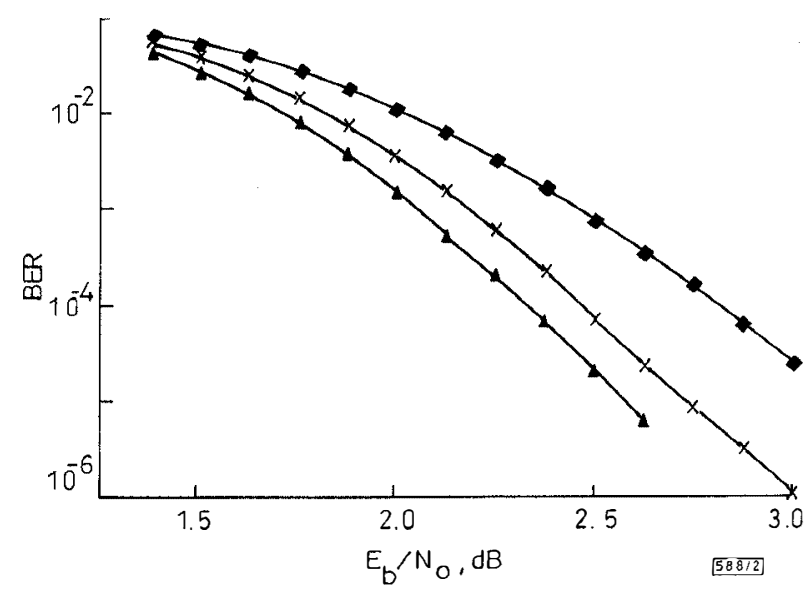

Fig. $2 B E R$ for $B C H(32,26,4)$ and $R S C(23,35)$ with $q=4, R=1 / 2$ and after four iterations

P. Adde, R. Pyndiah and C. Berrou

Indexing terms: Turbo codes, Convolutional codes, Block codes

The authors present the latest results on turbo codes which are built from a serial concatenation between a block code $(\mathrm{BCH})$ and a recursive systematic convolutional code. The performance on a Gaussian channel with QPSK modulation is evaluated.

Introduction: In 1993, Berrou et al. [1] showed that it was possible to transmit digital information at a rate close to channel capacity as predicted by Shannon in 1948 [2]. For this, a coding scheme based on the parallel concatenation of two recursive systematic convolutional (RSC) codes was used, associated with an original iterative decoding algorithm. This iterative decoding algorithm uses soft input and output decoding of the component codes. In 1994, Pyndiah et al. [3] proposed a new iterative decoding algorithm for decoding product codes, introduced by Elias [4] in 1954. This iterative decoding algorithm is also based on soft input and output decoding of the component codes. This new coding scheme showed exceptional performance for high code rates, typically for $R>0.75$. This new concept is known as a 'turbo-code' and is widely accepted [5]. In this Letter, we investigate the performance of iterative decoding in the case of a block code (extended $\mathrm{BCH}$ ) serially concatenated with a convolutional code (RSC).
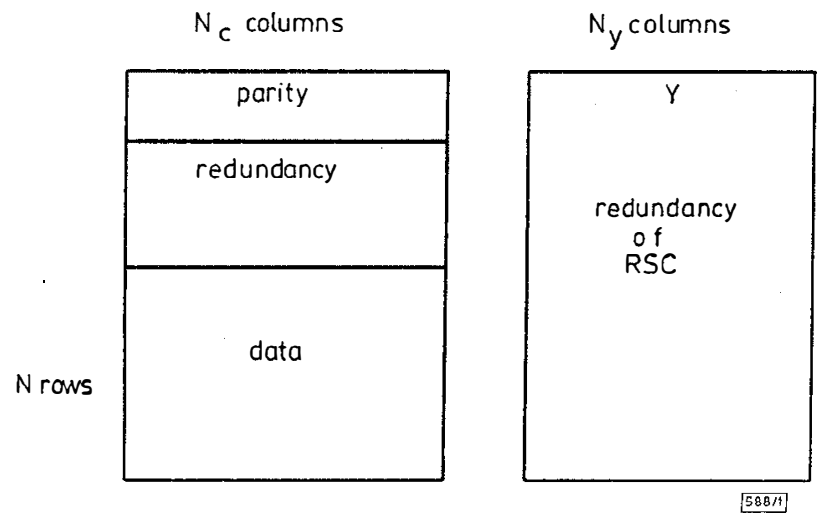

Fig. 1 Construction of hybrid turbo code

Construction of encoder: We consider the extended $\mathrm{BCH}(N, K, \delta)$. The hybrid turbo code is obtained by placing $N_{c} K$ information bits in an array of $K$ rows and $N_{c}$ columns. The $N_{c}$ columns are $\checkmark$ iteration 2

$x$ iteration 3

iteration 4

Bit error rate (BER) against signal to noise ratio on a Gaussian channel: Iterative decoding requires reliability information at the decoder outputs: for RSC codes, the Viterbi-based algorithm described in [6] is used and for extended $\mathrm{BCH}$ codes, the measurement of reliability is obtained from the log likelihood ratio estimation (LLR) [3]. Fig. 2 gives the BER of the hybrid turbo code built with extended $\mathrm{BCH}(32,26,4)$ and $\operatorname{RSC}(23,35)$ code. The symbols are encoded using $q=4$ bits (one bit for the sign and three for its reliability) and the global code rate is $R=1 / 2$.

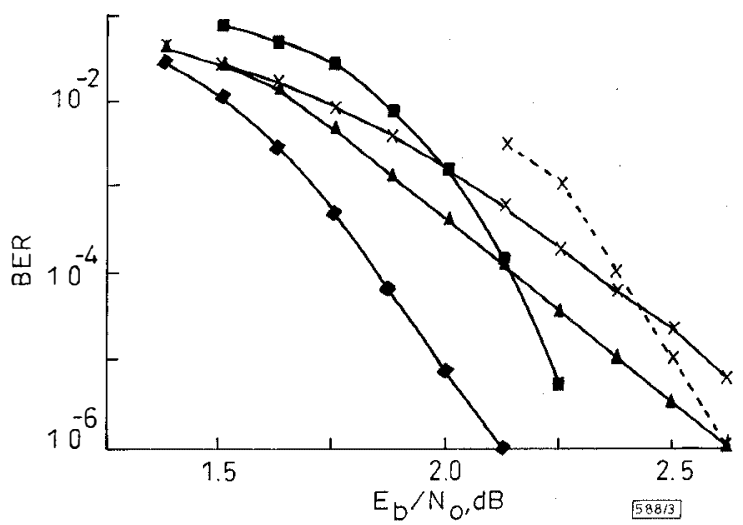

Fig. 3 Performance of different hybrid turbo codes with $q=4, R=1 / 2$ and after four iterations

- CC $(133,171)$ and $\mathrm{BCH}(64,57,4)$

- $\mathrm{CC}(133,171)$ and $\mathrm{BCH}(64,51,6)$

$\triangle \mathrm{CC}(23,35)$ and $\mathrm{BCH}(64,57,4)$

$\times \quad \mathrm{CC}(23,35)$ and $\mathrm{BCH}(32,26,4)$

$-X-C C(133,171)$ and $\mathrm{BCH}(255,233,16)$

Using the same code rate, we can associate different extended BCH coding with RSC $v=4(23,35)$ or $v=6(133,171)$. The results are reported in Fig. 3. The signal to noise ratio for a BER of $10^{-5}$ at iteration 4 is $2 \mathrm{~dB}$ from Shannon's theoretical limit for the serial concatenation of $\mathrm{BCH}(64,57,4)$ and $\operatorname{RSC}(133,171)$. We compared this association with the serial concatenation of the Reed-Solomon code RS $(255,223, t=16)$ and convolutional code CC $(133,171)$ [7] (in this case, the code rate is lower: 0.43). The coding gain is $\sim 0.5 \mathrm{~dB}$ for the hybrid turbo code. 
Variations with size of frame: If $N_{c}$ is modified, the size of the frame changes. Fig. 4 gives the BER for two hybrid turbo codes:

(i) $\operatorname{BCR}(32,26,4)$ and $\operatorname{RSC}(23,35)$ with 416 and 832 bit frame sizes

(ii) $\mathrm{BCH}(16,11,4)$ and $\operatorname{RSC}(23,35)$ with 88,176 and 264 bit frame sizes

For a 176 bit frame size, we have added the curve which gives the frame error rate (FER). Thus, hybrid turbo codes can be used for short blocks.

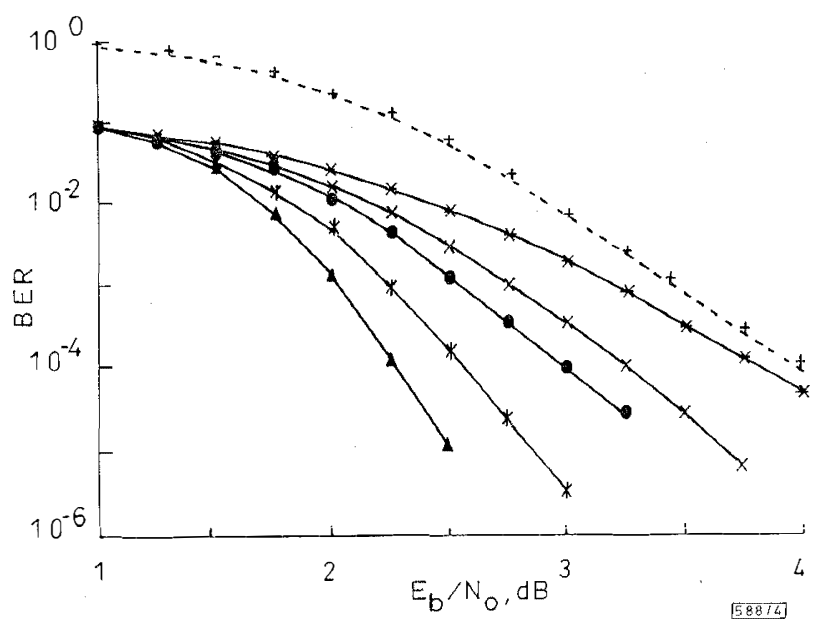

Fig. 4 BER against frame size and signal to noise ratio with $q=4, R=$ $1 / 2$ and after four iterations

$K \times N=416$

$\Delta K \times N_{c}^{c}=832$

$\times K \times N_{c}^{c}=88$

* $K \times N_{c}^{c}=176$

$K \times N_{c}=264$

$-\times-\mathrm{FER}^{c}=(176)$

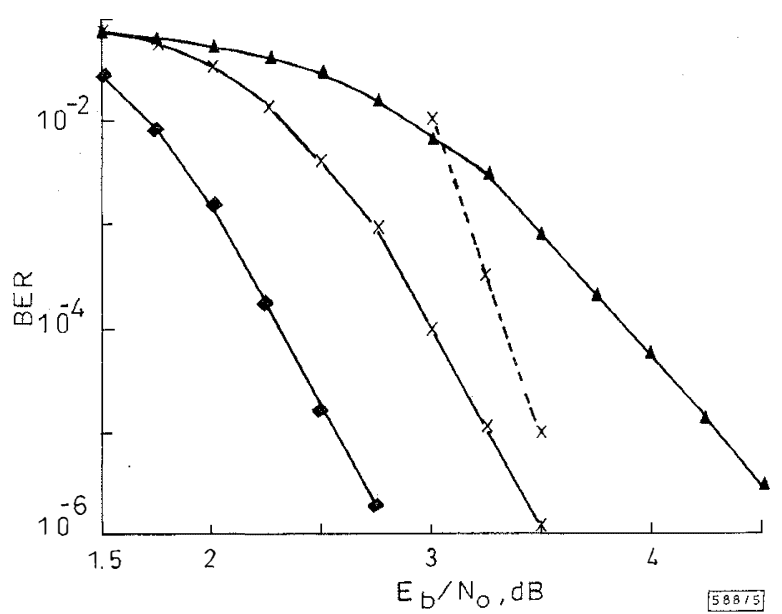

Fig. 5 BER against code rate and signal to noise ratio for $B C H(32,26$ $4)$ and $\operatorname{RSC}(23,35)$ with $q=4$ and after four iterations $(R=1 / 2,2 / 3$ and $3 / 4$ )

$R=1 / 2$

$\times R=2 / 3$

$\boldsymbol{\Delta} R=3 / 4$

$-X-\operatorname{CC}(133,171$ and $R=3 / 4)$ and $\operatorname{RSC}(255,239,8)$

Variations with $N_{y}$ : By puncturing $Y$, it is possible to change $R_{R S C}$ (and $R$ ). Fig. 5 gives the BER of the concatenation of $\mathrm{BCH}(32$, $26,4)$ and $\operatorname{RSC}(23,35)$, against different code rates. The results of the hybrid turbo code are compared with the serial concatenation of $\mathrm{CC}(v=6, R=3 / 4)$ and $\mathrm{RS}$ code $(255,239, t=8)$, used for digital HDTV [8].

Conclusion: We have given some results concerning the performances of hybrid turbo codes. They indicate that this serial concatenation can favourably replace the 'standard scheme' built with a $\mathrm{CC}$ and RS code. We also showed that they could be used for short blocks.
P. Adde, R. Pyndiah and C. Berrou (Télécom Bretagne, Technopôle Brest Iroise, BP-832, 29285 Brest, France)

E-mail: patrick.adde@enst-bretagne.fr

\section{References}

1 Berrou, C., GlavieuX, A., and thitimajshima, P.: 'Near Shannon limit error-correcting coding and decoding: Turbo-codes'. IEEE Int. Conf Comm. ICC'93, May 1993, Vol. 2/3, pp. 10641071

2 SHANNON, C.E.: 'A mathematical theory of communication', Bell Syst. Tech. J., July 1948, 27, pp. 379-423 (and pp. 623-656, October 1948)

3 PYNDIAH, R., GLAVIEUX, A., PICART, A., and JACQ, S.: 'Near optimum decoding of products codes'. Proc. IEEE GLOBECOM'94 Conf., San Francisco, November-December 1994, Vol. 1/3, pp. 339-343

4 ELIAS, P.: 'Error-free coding', IRE Trans. Inf. Theory, Sept. 1954, IT-4, pp. 29-37

5 'Special Issue on Turbo-Decoding', European Transactions on Telecommunications, September-October 1995, 6, (5)

6 BERROU, C., ADDE, P., ANGUI, E., and FAUDEIL, S.: 'A low complexity soft-output Viterbi decoder architecture'. Proc. IEEE ICC'93, Geneva, May 1993, pp. 737-740

7 POLLARA, F., and CHEUNG, K.-M.: 'Performance of concatenated codes using 8-bit and 10-bit Reed-Solomon codes'. TDA Progress Report 42-97, January-March 1989, pp. 194-201

8 MORELlo, A., MONTORSI, G., and visinTIN, M.: 'Convolutional and trellis coded modulations concatenated with block codes for digital HDTV'. Audio video digital radio broadcasting systems and techniques, Proc. 6th Tirrenia International Workshop on Digital Communications, Tirrenia, 5-9 September 1993, pp. 237-250 